\title{
Review on the Effectiveness of Aromatherapy Oils in the Learning of Autistic Children in an Educational Setting
}

\author{
Jasni Dolah ${ }^{1}$, Armeet Kaur Chal ${ }^{2 *}$, Aznan Che Ahmad ${ }^{3}$, Muhizam Mustafa ${ }^{4}$, \\ Ahmad Zuhairi Abdul Majid ${ }^{5}$, Nur Zaidi Azraai ${ }^{4}$, Norfarizah Mohd Bakhir ${ }^{4}$ \\ ${ }^{1}$ Universiti Sains Malaysia, \\ School of the Arts, Minden, 11800, Malaysia \\ ${ }^{2}$ UOW Malaysia KDU Penang University College, \\ Georgetown, 10400, Malaysia \\ ${ }^{3}$ Universiti Sains Malaysia, \\ School of Educational Studies, Minden, 11800, Malaysia \\ ${ }^{4}$ Universiti Sains Malaysia, \\ School of the Arts, Minden, 11800, Malaysia \\ *Corresponding Author amychahal94@yahoo.com
}

Received 8 September 2021; Accepted 21 October 2021; Available online 31 January 2022

https://doi.org/10.11113/humentech.v1n1.5

\begin{abstract}
:
This review was performed to determine the objective of therapeutic intervention on the learning of autistic children. This literature review aimed at addressing two critical issues: (1) the benefits of aromatherapy oils, including the understanding of its effect on ASD children in literature, and (2) the significance of its effect on their learning. An extensive search was carried out on various online databases, including ERIC, ProQuest Education Journals, and Scopus using the following phrases: ("aromatherapy oils" or "aromatherapy oils in learning") and ("ASD children"). The studies selected for this review examined therapeutic interventions to improve the learning of autistic children and were analyzed using the content analysis method. Despite appeals for further studies in the 1980 and 1990s, no scientific evidence is available to substantiate the use of aromatherapy oils for learning. Although there are increased studies on aromatherapy oils, the impact on learning, especially for ASD children, has not been investigated. Furthermore, the methodological details on the use of aromatherapy oils in education remain poor. This study demonstrated that traditional methods for treating people with autism are not the only approach and that there is an alternative method using essential oils that is both healthy and toxic-free. The efficiency of basic oil was refuted, and clear evidence of essential oil benefits for people with autism understand was presented. This study would be of great interest to parties including parents of autistic children and organizations that assist people with autism.
\end{abstract}

Keywords: Aromatherapy oils; ASD; Children; Learning; Therapeutic intervention 


\section{Introduction}

Autism is a set of symptoms that appear across the spectrum, such as communication, social connection, sensory integration, a stereotype, and overly centered interests. This diverse range of strengths and weaknesses contributes to the formation of a distinctive profile. Because autism has such a significant impact on young children, socially, emotionally, and academically, parents and clinicians alike are constantly striving to find effective treatment approaches [1].

According to Cronbach [2], people should learn that in the early 1900s, researchers including Thorndike and Woodworth facilitated a change in the academic mindset, shifting to assessing the impact of environmental change upon learning in order to improve results [3]. This environmental concern has long been used to assist teachers in building productive classrooms [4]. Teachers need to carefully consider the context, atmosphere, and experiences that improve the learning of these students while designing environments that allow students with disabilities to learn.

The healthcare community has been urged to develop specific instructional strategies to better understand how different environmental factors affect the learning and success of autistic students [5]. The needs of an autistic child are often very complex that they are difficult to understand and fulfilled in a community setting.

Though no cure has been found for ASD, researchers have developed and tested a number of interventions aimed at young children. Treatments like these may help with symptoms while also enhancing cognitive function and daily living skills in the child so they have the best chance of thriving and contributing to their community. People with ASD have unique strengths and challenges in social communication, behavior, and cognitive ability because of the differences in how ASD affects each individual. A child's individual needs may be addressed through interventions mediated by parents as well as multidisciplinary treatment plans [6].

Essential oils are plant extracts that promote tranquility in the mind and balance the emotional and physical states ofan individual. Extraction of plant oils is typically performed through distillation and their properties remain unaltered in essential oil form. Oils are extracted from several plant parts including the flower (lavender), stem (lemongrass), leaf (eucalyptus, geranium), or bark (cinnamon). Several essential oils are believed to offer specific mind and body therapeuticeffects.

Essential oils derived from rose flowers and herbs, known as tea trees, are widely believed to have antidepressant, bacteriostatic, or sedative properties [7]. There are various ways essential oils can be applied, including vaporization (as oils, creams, or lotions), with all of them safe for consumption (placed in bath or foot spas). Aromatherapy and essentialoils are used by people with learning disabilities to improve sensory sensitivity and communication in a variety of situations. The aim of this study is to demonstrate the effectiveness of aromatherapy oils in an educational context for autistic children by reviewing the challenges that autistic children face in learning as well as the benefits of essential oils for autistic children

\section{Autism Spectrum Disorder}

Essentially, Autism Spectrum Disorder is a developmental disability that can result in severe social, communication, and behavioral problems. This can lead to social contact issues, trouble relating to people, objects, and events, as well asrepeated body movements or behaviors. The "spectrum of ASD", as defined in the APA report [8], implies that people with ASD have a variety of deficiencies, each with their own characteristics and needs.

Autism is a developmental condition that causes children to be unable to communicate verbally, resulting in social difficulties. Autistic people are impeded by their thoughts and may also experience sensory problems. Early and effectiveintervention is important to help a person with autism in becoming more independent and integrated into the community. Children who receive treatment (a well-balanced special diet and natural therapies) reflect better chances of success. Thisdisorder exists on a continuum that has shown variations in the growth of children as they advance into adulthood [6].

Autism is becoming more prevalent in Malaysia, yet the level of awareness and understanding of this spectrum of disorders remains poor. The children are poorly educated on this disorder, owing to the lack of knowledge about autismamongst parents and the community [9]. The lack of knowledge on autism is the main reason why society still does notunderstand autism [10]. 
Intervention is based on developmental psychology theories that help resolve behavioral issues in autistic children. In the intervention programmed, the known missing connections in an autistic child are targeted, which requires persistence, repeated implementation, and consistency before improvements are apparent. As a result, many parents are unaware of this and solely monitor their children through alternative medication or approaches that are out of sync with the actual development of their child. Understanding children's cognitive, physical components, and language development will initiate spontaneous collective efforts among all caregivers, particularly parents, who will comprehend the actual reasons for the continuous use of therapy programmed to help their child overcome autism.

\section{Challenges Autistic Children Face in Learning}

Asperger's Syndrome or ASD refers to individuals who have age-appropriate language and intelligence but lack social and adaptive skills, which are apparent at an early age [11]. Therefore, strategies for improving learning that will result in beneficial educational changes for ASD children are necessary [12]. Hodge et al. [13] examined cerebral damage in autistic children aged 6 to 13. The deficiency is caused by the left part of the lobules, which affects communication abilities, memory, academics, and cognitive areas [14]. Previous study reported that autistic children are highly intelligent, but their IQ levels do not remain constant and are dependent entirely on the circumstances. Therefore, appropriate interventions are necessary and must be correctly provided. Although autistic children are incapable of remembering long phrases and learn routine actions, they are able to solve puzzles and perform arithmetic calculations. In addition, Warm et al. [15] found that autistic children have comparatively weak memory for complex visual, verbal knowledge, and spatial workingmemory.

Measures for improving learning that will result in beneficial educational changes for ASD children are required. Communication issues, limited focus, concentration struggles, anxiety, violence, aggression, inattention, hyperactivity, and impulsivity can all be present in autistic children with learning difficulties [16]. A better understanding of how autism affects learning is a critical step to overcome these challenges. There are limited studies into how best to assist the support faculty in accommodating students with ASD in their classrooms [17]. Therefore, this paper aims to examine how therapeutic intervention can improve learning, especially for ASD children.

\section{The Benefits of Aromatherapy Oils}

Aromatherapy consists of the words aroma (fragrant) and therapy (treatment). This form of therapy, which was developed at the end of the 20th century, has gained popularity in the 21 st century. Essential oils are now widely used inmedical, cosmetic, herbal, fragrant, and spiritual applications. In order to improve the understanding of our surroundings, the information acquired from seeing, hearing, touching, tasting, and smelling is important. Aromatherapy stimulates feelings and scents, as well as provides more than just mental and physical health, creating new ways for people to interactwith their environment, particularly for people with learning difficulties.

People with learning difficulties may also have other physical and sensory disabilities. There are a high number of individuals with intellectual disabilities who are also sensory impaired, with $48 \%$ having both senses impaired [18]. People with learning disabilities face increased stress due to their inability to communicate, owing to limited choices in their daily life or new experiences and learnings. Aromatherapy can help a troubled person in relaxing and falling asleep, as well as in relieving irritability, frustration, stress, and anger.

Aromatherapy and massage are holistic experiences that combine senses of scent and touch with a person's physical, psychological and spiritual aspects. These therapies, when combined, have to potential to significantly improve the lives of people with learning difficulties. This type of massage incorporates the use of massage tools, creams, lotions, and fragrant massage oils, to provide a sense of touch, which has been proven to increase the ability and motivation of the person to connect and socialize.

Aromatherapy can also be used in schools as part of the Science Programmed of the National Curriculum, which involves responding to sensory stimuli as well as expressing interest in and exploring materials. Essential oils have beenconsidered to be utilized as antidepressants, stress relievers, sedatives, stimulants, aids to communication, and sleep inducers [19]. According to research conducted at Warwick University, people are able to identify distinct fragrances with various emotions [20].

Many studies have shown that aromatherapy reduces anxiety, pain, and hypertension [21]. Horowitz [22] reported that aromatherapy has positive effects on mood, physiology, and behavior, which was similar in other studies [23-24]. For centuries, people have believed that certain essential oils can boost and revitalize fatigued 
minds and bodies. A study conducted in Japan found that exposure of machine operators to lavender scent reduced errors by $20 \%$, whereas exposure to the lemon's energizing scent reduced errors were by $54 \%$. The majority of these papers discuss the exceptional healingeffects of essential oils, but not in the context of autism. Most of the evidence regarding the use of essential oils in autism was obtained from case studies and articles by parents, caregivers, and practitioners.

\section{The Function of Aromatherapy}

Aromatherapy has made way into electronic devices, such as diffusion lamps, ultrasonic spray machines, and essential oils burners. Containers are used in many locations to obtain fragrances for physical and psychological cleansing. For thousands of years, essential oils have been utilized for their beneficial and healing effects on the body, mind, and spirit. Various approaches, such as inhalation, massage or skin surface treatments, are used, although they arerarely taken internally. Aromatherapy is important for inhalation and the oils have been applied to treat mental and physical balance. The oils can be extracted from various plant parts and have previously been shown to work in a numberof ways.

Table 1 . The different types of aromatherapy oil applications

\begin{tabular}{ll}
\hline Classification & \multicolumn{1}{c}{ Description } \\
\hline Cosmetic & $\begin{array}{l}\text { Some essential oils are used for cosmetic products for the skin, body, face, and hair. These } \\
\text { products are used for a variety of purposes such as cleaning, moisturizing, drying, and toning. } \\
\text { Rene-Maurice Gattefosse, the founder of modern aromatherapy, has applied essential oils for } \\
\text { patient massages during surgery, which has been proven by clinical trials. }\end{array}$ \\
Psycho & $\begin{array}{l}\text { A method that helps the user in achieving different emotions and moods using aromatherapy. } \\
\text { In this treatment, the oils are inhaled directly through an infusion in the patient's room. } \\
\text { Involves the absorption of essential oil molecules, or by adding or rubbing essential oils to the } \\
\text { skin. } \\
\text { Requires essential oils to be inhaled, leading to better emotional health, tranquility, } \\
\text { Olfactory }\end{array}$ \\
relaxation, or revitalization of the body.
\end{tabular}

\section{The Effectiveness of Aromatherapy in Learning}

Children were less agitated and slept for longer periods when essential oils were added into their bathwater, appliedto their backs, used for massage, or placed in a diffuser at night. Both parents and children reported feelings of calm when essential oils were sprayed or diffused in the environment [25]. A study conducted in Thailand that investigated the beneficial effects of Thai Traditional Massage (TTM) on hyperactivity, inattention, and sleeping behavior, discovered that only there were only apparent improvements in anxiety [26]. Massage therapy has been shown to reduce stereotypical behavior and touch aversions, as well as enhance sleep quality, classroom attentiveness, and social interaction. According to a new study, massages given by parents reduce children's sleeping problems and improve behavior control[27].

Various studies have shown the psychophysiological aspects of odors, but cognitive functions have yet to be fully understood. According to previous reports, olfactory stimuli affect attention significantly [28-32]. Olfactory stimuli are able to increase attentiveness and focus, both of which are vital learning variables [33-35]. Based on aroma studies and medical information, selected olfactory stimuli can be discharged into the school environment at various stages of learning, which at the very least, will increase learner concentration.

Türnüklü [36] examined the impact of essential oils on vigilance or sustained attention tasks. In the study, there were three different situations, and odors, either the essential of Muguet or Peppermint (control), were available in various circumstances. These findings led to the conclusion that oil administration has aided in maintaining attention and completing difficult workouts. It has been reported that scents will put certain students in the right state of mind for learning. According to the study, students have less anxiety and are able to achieve a clearer, more attentive state of learning that can aid them in storing information when they are exposed to a relaxing or familiar scent. Furthermore, they may also begin to associate certain scents with certain experiences, which can help to enhance memory recall [37-42]. Another study that focused on using essential oils for brain stimulation discovered that alertness was increased among eleventh-grade females. This provided substantial evidence that aromatherapy has a positive correlationwith alertness in classroom participation [35]. 
Memory is a critical component for learning as it is the foundation of all perception and learning, and aromas have been shown to improve memory. It demonstrated that people who lost their olfaction have difficulty recalling, suggesting that an olfactory stimulus can aid memory. The information gained by olfactory exposure is highly impactful, resulting in long-term memory. Aromatherapy may aid memory by matching messages with smells, creating smells in the learning

environment, or repeating classes with scents.

A study involving 79 high school students between 13 and 17 years old was conducted to analyses the effects of essential oils on short-term human image and numerical memory. The participants were split into three groups: the control group, the 'lavender' group (in which the essential oil of lavender was used), and the 'rosemary' group. When compared to the regulation of essential rosemary and lavender oils, visual memory was significantly improved. In addition, numerical memorization was enhanced by the inhalation of the essential rosemary oil [43].

In a 15-minute experiment, 40 school children were asked to complete standardized memory tests. The findings revealed that those who played memory games in a rosemary-scented room outperformed those in an unflavored room. Active chemical compounds in essential oils are absorbed into the bloodstream and transported to the brain where they can affect systems associated with memory [44]. Some data regarding the impact of olfactory stimuli on learning can befound in literature, although its framework has currently not been properly defined [4547].

There are many beneficial effects of olfactory stimuli, which may assist in facilitating learning [48]. Taking into account the students' genetic, individual, and cultural aspects, using the appropriate scents to aid learning can create a more peaceful classroom environment for students than they are now. Therefore, the use of aromas, which are able to aidmemory and have impacts on the perception of surroundings during the process of learning, should be encouraged [49]. Essential oils can make a substantial difference to the cognitive and affective learning of both normal and learning-disabled students.

There are studies on the functions of olfactory stimuli, such as emotional processing and long-term memory organization [50-51]. Complicated ideas can be made more understandable by pairing them with aromas. In addition, matching learning concepts with good scents increases the efficiency of emotional learning in classrooms. When considering how olfactory stimuli aid memory and mental images [52], olfactory stimuli may be effective in promoting the coding of learning process messages. Certain olfactory sensations can be used as a lifesaving association factor in emergencies as they are very simulative. Preparing individuals for life, and each of its stages are important, which is theaim of education.

In conclusion, aromatherapy oils positively impact learning, especially in terms of memory and attention. Furthermore, oils such as lavender, rosemary, and peppermint were repeatedly used in most of the studies to determine their effects on learning.

\section{The Use of Aromatherapy Oils in the Learning of Autistic Children}

According to a previous study, there are two ways in which essential oil helps an autistic child: to create contact and to release emotion. The use of lavender, geranium, and clary sage has been suggested to reduce stress and anxiety. Studies have also shown that massage therapy can put autistic children at ease sufficiently for them to focus in class. While there is favorable evidence, the number of studies is still limited and requires further research [53].

The use of essential oils has been suggested to promote brainwave activity balance and neurological growth as partof autism therapy. Beneficial results were observed in a two-year case study when medicinal essential oils were inhaledthree times a day for 30 days using a diffuser by children who had previously been diagnosed with ASD [54]. Lavender, vetiver, and cedar wood were the most important oils used in that study, with inhalation of these oils revealing that the brain waves of the children were restored to normal patterns, and there were improvements in their performance and behavioral patterns. The aromas of essential oils have a significant capability of stimulating the brain's limbic region.

The use of aromatherapy in children with disabilities helped them come out of their shells and facilitated experiences and relationships with others [55]. Furthermore, the sleep patterns of the same children also improved. According to [56], aromatherapy can be used to calm an anxious person, and suggested oils, such as lavender and sandalwood, be used frequently to avoid causing distress or deprivation. A study by Ellwood [57] used aromatherapy, 
as well as foot and hand massages, on six primary school-aged, non-verbal children with autism. According to the study, lavender oil helped the children toappear more at ease, and gentle massages reduced the tactile defense of the children as well as built their trust in adults. The use of oil and massages resulted in the development of improved communication skills. In addition, Richler [58] proposed similar ideas for improving interactions using aromatherapy massages.

Sanderson and Ruddle [59] examined whether shared attention behavior in a group of four children with autistic spectrum disorders and significant learning disabilities could be improved using aromatherapy massage. Aromatherapy massage was included into the children's day-to-day schedule and their reactions were observed. The findings suggested that there was an improvement in the behavior of children during aromatherapy massages and that other aspects of their behavior also showed changes throughout the process. Other advantages involved include enhancing the use of eye contact to attract attention, exchanging activities and materials with adults, developing tolerance to the physical closeness of others, and initiating (request for) massage through non-verbal means.

Another study carried out a case study on autistic children aged between 7 and 15 years that aimed to examine how lavender oil in diffusers affected the development of communicative abilities in autistic children [60]. The research included three sessions of 15 to 20 minutes per week over the course of four months. There was a marked improvementin the case of two girls, but the other children did not display a similar level of improvement, and one did not show any improvement. According to the researchers, the aromatherapy sessions helped to relax the children, which improved theirlearning. Research carried out by Christie [61] on the effects of essential oils on the academic and social skills of an autistic child. The researchers focused on using 12 different essential oils to support the development of the child, with a greateremphasis on academic and social competencies, over a six-to-eight-month period. The outcome was evaluated and analyzed to determine the best reactions from the study. After the intervention, more positive signs were observed, including increased openness to communicated more and a greater willingness to deal with difficult situations. This review showed that essential oils have a positive effect on learning response. However, there are limited studies on autistic children as the majority of studies focused on healthy individuals. Typical sensory functioning in ASD has been extensively studied over the past decade for the visual, tactile, and auditory systems, but very little is known about olfaction in ASD [62].

\section{Conclusion}

It was surprising to discover that there were only a handful of research studies on therapeutic interventions in the context of education in the literature review. Furthermore, there were also limited studies on the treatments for children with ASD, with the few available studies primarily focusing on the learning of healthy individuals rather than ASD children. Based on the literature review, it was found that ASD children should receive therapeutic interventions in an educational setting. To date, the majority of non-pharmacological interventions performed on ASD children were appliedbehavior analysis, speech, language, communication intervention, occupational therapy, and cognitive behavior therapy.

More studies in this area are required to determine the complete effects of aromatherapy and various fields that it can be used as an educational intervention. It was challenging to investigate the whole aspect of aromatherapy because many elements must be considered. Nevertheless, it is implied that the essential oils used in aromatherapy were the most effective alternative treatments for the brain, body, and emotional disturbance. Although there are growing indications that essential oils have beneficial effects on the learning of healthy individuals, further research is needed to establish their influence on autistic individuals. This will enable teachers to create classrooms that are both accommodating and enriching.

There were significant opportunities for increased collaborative research for further in-depth investigations and progress beyond the low dose concept of essential oil applications. This study outlined a case for the beneficial effects ofaromatherapy on people suffering from learning difficulties. Increased understanding in this area will help educators in planning instruction and environment settings that promote learning. Due to inadequate studies on the impact of therapeutic intervention on autistic children, it was vital to investigate the effects of aromatherapy. This study contributedto the existing research by demonstrating the role of essential oils in enhancing learning.

A comprehensive and thorough literature search was performed to identify as many comparable research as possible; nevertheless, the review was not extensive enough. There was a limitation to the findings using keyword searches in thedatabases and it was logical to infer those other related studies have not been discovered. Studies in the literature studies that did not show up in the searches were excluded from this review. 


\section{Acknowledgment}

This study was funded by a grant (1001/PSENI/8016103) from the Division of Research \& Innovation (RCMO), Universiti Sains Malaysia (USM) under the 'Skim Siswazah Pembantu Penyelidikan' (SSP) grant. The author and co- author would like to show appreciation to RCMO for their willingness to cooperate and support this research.

\section{References}

[1] D. J. Cohen and F. R. Volkmar, Handbook of Autism and Pervasive Developmental Disorders, 2nd ed., New Jersey: John Wiley and Sons Inc, 1997.

[2] L. Cronbach, The two disciplines of scientific psychology, American Psychologist, 1957, 12(11):671-684. https://doi.org/10.1037/h0043943

[3] L. Hall, The response of children with autism to preferred prosody during instruction, Focus on Autism and Other Developmental Disabilities, 2003, 18(2):95-104. https://doi.org/10.1177\%2F108835760301800203

[4] S. R. Anderson, M. Taras and B. O. Cannon, Teaching new skills to young children with autism. Behavioral Intervention for Young Children with Autism: A Manual for Parents and Professionals, 1996, 181-194.

[5] H. Welzl and O. Stork, Cell adhesion molecules: Key players in memory consolidation?, News in Physiological Sciences, 2003, 18:147-150. https://doi.org/10.1152/nips.01422.2002

[6] K. Piravej, P. Tangtrongchitr, P. Chandarasiri, L. Paothong and S. Sukprasong, Effects of Thai traditional massage on autistic children's behavior, The Journal of Alternative and Complementary Medicine, 2009, 15(12):1355-1361. https://doi.org/10.1089/acm.2009.0258

[7] A. Teerling and E. P. Koster, Fragrance and mood. A study on the effect of fragrances on the human mood. University of Utrecht: Report Psychological Laboratory, 1988.

[8] APA and A. P. Diagnostic and Statistical Manual of Mental Disorders, 4th ed., Washington: Psychiatric Association, 1994.

[9] H. Azizan, 2008. The Burden of Autism. The Star Online, Retrieved January 30, 2021, from https://www.thestar.com.my/opinion/letters/2008/04/27/the-burden-of-autism/

[10] D. Jasni, W. Y. Wan Ahmad Jaafar and S. C. Toh, A preliminary investigation: Potential of interactive multimedia learning awareness (IMLA) in enhancing awareness among autism parents in Malaysia, Electronic Journal of Computer Science and Information Technology, 2011, 3(1):19-25.

[11] M. Ghaziuddin, Defining the behavioral phenotype of asperger syndrome. Journal of Autism and Developmental Disorders, 2008, 38:138-142. https://doi.org/10.1007/s10803-007-0371-7

[12] L. Catherine and B. Sarah, National Research Council, Educating Children with Autism, Washington: National Academy Press, 2001.

[13] S. M. Hodge, N. Makris, D. N. Kennedy, V. S. Caviness Jr., J. Howard, L. Mcgrath, S. Steele, J. A. Frazier, H. Tager-Flusberg and G. J. Harris, Cerebellum, language, and cognition in autism and specific language impairment, Journal of Autism and Developmental Disorders, 2009, 40(3):300-316. https://doi.org/10.1007/s10803-009-0872-7

[14] S. Solomons, Using aromatherapy massage to increase shared attention behaviours in children with autistic spectrum disorders and severe learning difficulties, British Journal of Special Education, 2005, 32(3):127-137. https://doi.org/10.1111/j.0952-3383.2005.00385.x

[15] S. J. Warm, N. W. Dember and R. Parasuraman, Effects of olfactory stimulation on performance and stress in a visual sustained attention task. Journal of The Society of Cosmetic Chemists, 1991, 42:199-210.

[16] M. Moss, V. Earl, L. Moss and T. Heffernan, Any sense in classroom scents? Aroma of rosemary essential oil significantly improves cognition in young school children, Advances in Chemical Engineering and Science, 2017, 7(4):450-463. https://doi.org/10.4236/aces.2017.74032

[17] Y. Bolourian, K. M. Katherine, K. M. Stavropoulos and J. Blacher, Autism in the Classroom: Educational Issues across the Lifespan, in: F. Michael, Autism Spectrum Disorder, IntechOpen: London, 2019.

[18] M. J. Gill and S. L. Harris, Hardiness and social support as predictors of psychological discomfort in mothers of children with autism. Journal of Autism and Developmental Disorders, 1991, 21(4):407-416. https://doi.org/10.1007/BF02206867

[19] B. Reichow, E. E. Barton, B. A. Boyd and K. Hume, Early intensive behavioral intervention (EIBI) for young children with autism spectrum disorders (ASD), The Cochrane Database of Systematic Reviews, 2018, 17(10):1-44. https://doi.org/10.1002/14651858.CD009260.pub2

[20] R. Tisserand, Aromatherapy for everyone, London: Arkana, 1980.

[21] J. Burt and C. Cole, Delivering aromatherapy and massage in a day centre: A project that provided hand and foot treatments proved successful. Christine Cole and Jennifer Burt discuss the potential for health 
Dolah et al. /Journal of Human Centered Technology 1: 1 (2022) 1-9

professionals to develop a similar scheme. Learning Disability Practice, 2011, 14(10):25-29. https://doi.org/10.7748/LDP2011.12.14.10.25.C8862

[22] J. L. Horowitz, Applied nonparametric instrumental variables estimation, Econometrica, 2011, 79(2):347-394. https://doi.org/10.3982/ECTA8662

[23] S. R. Herz, Aromatherapy facts and fictions: A scientific analysis of olfactory effects on mood, physiology and behavior, The International Journal of Neuroscience, 2009, 119(2):263-290. https://doi.org/10.1080/00207450802333953

[24] L. A. Berman, Estimating the population of survivors of suicide: Seeking an evidence base, Suicide and LifeThreatening Behavior, 2011, 41(1):110-116. https://doi.org/10.1111/j.1943-278X.2010.00009

[25] A. L. Cullen-Powell, H. J. Barlow and D. Cushway, Exploring a massage intervention for parents and their children with autism: the implications for bonding and attachment, Journal of Child Health Care, 2005, 9(4):245-255. https://doi.org/10.1177/1367493505056479

[26] I. Obrusnikova and S. R. Dillon, Challenging situations when teaching children with autism spectrum disorders in general physical education, Adapted Physical Activity Quarterly, 2011, 28(2):113-129. https://doi.org/10.1123/apaq.28.2.113

[27] M. S. Lee, J. Kim and E. Ernst, Massage therapy for children with autism spectrum disorders: A systematic review, The Journal of Clinical Psychiatry, 2011, 72(3):406-411. https://doi.org/10.4088/JCP.09r05848whi.

[28] R. Sprinkle, The power of aroma and olfactory experience in the classroom, Teaching English in the Two Year College, 1999, 27(2):188-193.

[29] R. A. Baron, Environmentally induced positive effects: Its impact on self-efficacy, task performance, negotiation and conflict, Journal of Applied Social Psychology, 1990, 20(5):368-384. https://doi.org/10.1111/j.1559-1816.1990.tb00417.x

[30] J. Degel and E. P. Köster, implicit memory for odors: A possible method for observation, Perceptual and Motor Skills, 1998, 86(3):943-952. https://doi.org/10.2466/pms.1998.86.3.943

[31] H. Sanderson, J. Harrison and S. Price, Aromatherapy and Massage for People with Learning Difficulties, $1^{\text {st }}$ ed., San Diego:Hands On Publishing, 1991.

[32] E. Y. L. Kelvin, Ruminations on smell as a sociocultural phenomenon, Current Sociology, 2005, 53(3): 397417. https://doi.org/10.1177\%2F0011392105051333

[33] C. J. Stoodley and J. D. Schmahmann, Functional topography in the human cerebellum: A meta-analysis of neuroimaging studies, Neuroimage, 2009, 44(2):489-501. https://doi.org/10.1016/j.neuroimage.2008.08.039

[34] E. Barocelli, F. Calcina, M. Chiavarini, M. Impicciatore, R. Bruni, A. Bianchi and Ballabeni V, Antinociceptive and gastroprotective effects of inhaled and orally administered Lavandula hybrida Reverchon "Grosso" essential oil, Life Sciences, 2004, 76(2): 213-223. https://doi.org/10.1016/j.lfs.2004.08.008

[35] S. J. Manuel, M. Syazwan, C. W. Han, W. N. Fazliyana and M. B. Awal, Peppermint and lavender essential oils: are they therapeutic aromas for attention and memory?, The Internet Journal of Alternative Medicine, 2014, 9(1):1-6.

[36] A. Türnüklü, lköretimde sınıf düzeni. Yaşadıkça Eğitim Dergisi, 2000, 65:36-40.

[37] R. S. Herz, The effects of cue distinctiveness on odor-based context dependent memory, Memory \& Cognition, 1997, 25(3):375-380. https://doi.org/10.3758/bf03211293

[38] R. Hudson and H. Distel, The individuality of odor perception in: C. Rouby, B. Schaal, D. Dubois, R. Gervais and A. Holley, Olfaction, Taste and Cognition, Cambridge University Press: Cambridge, 2002, 408-420.

[39] R. H. Finnegan, Communicating: The Multiple Modes of Human Interconnection, England: Routledge, 2002.

[40] M. J. R. Howes and P. J. Houghton, Plants used in Chinese and Indian traditional medicine for improvement of memory and cognitive function, Pharmacology, Biochemistry, and Behavior, 2003, 75(3):513-527. https://doi.org/10.1016/s0091-3057(03)00128-X

[41] S. V. Toller and G. H. Dodd, Perfumery: The Psychology and Biology of Fragrance, Netherlands: Springer, 1990.

[42] R. Lamprecht and J. LeDoux, Structural plasticity and memory, Nature Reviews Neuroscience, 2004, 5:45-54. https://doi.org/10.1038/nrn1301

[43] O. V. Filiptsova, L. V. Gazzavi-Rogozina, A. Timoshyna, O. I. Naboka, Y. V. Dyomina and A. V. Ochkur, The effect of the essential oils of lavender and rosemary on the human short-term memory. Alexandria Journal of Medicine, 2018, 58(1):41-44. https://doi.org/10.1016/j.ajme.2017.05.004

[44] M. Moss, J. Cook, K. Wesney and P. Duckett, Aromas of rosemary and lavender essential oils differentially affect cognition and mood in healthy adults, The International Journal of Neuroscience, 2002, 113(1):15-38. https://doi.org/10.1080/00207450390161903

[45] J. D. Johnson, Effects of communicative factors on participation in innovations, International Journal of Business Communication, 1990, 27(1):7-23. https://doi.org/10.1177/002194369002700102

[46] K. B. Given, Beslenmenin Öğrenmeye etkisi . Journal of Education for Life, 1999, 63:37-40.

[47] N. T. J. Tildesley, D. O. Kennedy, E. K. Perry, C. G. Ballard, K. A. Wesnes and A. B. Scholey, Positive modulation of mood and cognitive performanca following administration of acute doses of Salvia 
Dolah et al. /Journal of Human Centered Technology 1: 1 (2022) 1-9

lavandulaefolia essatial oil to healthy young volunteers, Physiology \& Behavior, 2005, 83(5):699-709. https://doi.org/10.1016/j.physbeh.2004.09.010

[48] R. J. Hofmann, Extended latent partition analysis, Educational and Psychological Measurement, 1987, 47(1):39-44. https://doi.org/10.1177/0013164487471005

[49] A. W. Donald, M. J. Lauriann, V. S. Ravi and A. B. Clint, Olfactory use in virtual environment training, 2005, 2(3):1-16.

[50] Aromafloria. Aroma Communication: First Brain, 2004, http://www.aromafloria.com/FirstBrain.htm.

[51] I. Brosh and E. Barkai, Learning-induced long-term synaptic modifications in the olfactory cortex, Current Neurovascular Research, 2004, 1(4): 389-395. https://doi.org/10.2174/1567202043362090

[52] A. Bodnar, R. Corbett and D. Nekrasovski, AROMA: Ambient awareness through olfaction in a messaging application, Proceedings of the 6th International Conference on Multimodal Interfaces, 2004, 183-190. https://doi.org/10.1145/1027933.1027965

[53] D. L. Williams, G. Goldstein and N. J. Minshew, The profile of memory function in children with autism, Neuropsychology, 2006, 20(1):21-29. https://dx.doi.org/10.1037\%2F0894-4105.20.1.21

[54] T. Friedmann, Attention deficit and hyperactivity disorder (ADHD), JAMA, 2002.

[55] P. Holden-Peters, The gentle touch, Special Children, 1993, 30.

[56] J. Harrison, Aromatherapy and autism. Communication, Winter, 1996.

[57] J. Ellwood, Aromatherapy and autism: A case study. International Therapist, 2001, 14-15.

[58] J. Richler, S. L. Bishop, J. R. Kleinke and C. Lord, Restricted and repetitive behaviors in young children with autism spectrum disorders, Journal of Autism and Developmental Disorders, 2007, 37(1):73-85. https://doi.org/10.1007/s10803-006-0332-6

[59] H. Sanderson and J. Ruddle, Aromatherapy and occupational therapy, British Journal of Occupational Therapy, 1992, 55(8): 310-314.

[60] K. Archana, M. Sumeet, P. Prithvi, Effects of aromatherapy on the development of communication skills in children with autism, 2006, 1-11. https://doi.org/10.13140/2.1.4188.0006

[61] L. G. Christie, Use of essential oils on the development of academic and social skills in an autistic child. Thesis for Master of Education. University of Canterburry, 2016, 1-90. https://doi.org/10.13140/RG.2.2.10783.18080

[62] A. C. Luisier, G. Petitpierre, C. Ferdenzi, A. C. Bérod, A. Giboreau, C. Rouby and Moustafa Bensafi, odor perception in children with autism spectrum disorder and its relationship to food neophobia, Frontiers in Psychology, 2015, 1;6:1830. https://doi.org/10.3389/fpsyg.2015.01830 